\title{
Association of public physical activity facilities and participation in community programs with leisure-time physical activity: does the association differ according to educational level and income?
}

André O. Werneck ${ }^{1 *}$, Adewale L. Oyeyemi ${ }^{2}$, Raphael H. O. Araújo ${ }^{3}$, Luciana L. Barboza ${ }^{4}$, Célia L. Szwarcwald ${ }^{5}$ and Danilo R. Silva ${ }^{6}$

\begin{abstract}
Background: Our aim was to analyze the association of the presence of public physical activity (PA) facilities and participation in public PA programs with leisure-time PA, with an emphasis on the moderating role of educational level and income.

Methods: We used data of 88,531 adults (46,869 women), with a mean age of $47.2 \pm 17.1$ y, from the 2019 Brazilian National Health Survey. Leisure-time PA (dichotomized considering $150 \mathrm{~min} /$ week), the presence of a public PA facility near the household (yes or no), participation in public PA programs (yes or no), educational level (divided into quintiles) and per capita income (divided into quintiles) were all self-reported through interviews. Adjusted logistic regression models were used for the analyses.

Results: The presence of public PA facilities near the household and the participation in public PA programs were associated with higher leisure-time PA among all quintiles of income and educational level. However, multiplicative interactions revealed that participating in PA programs [Quintile (Q) 1: OR: 13.99; 95\%Cl: 6.89-28.38 vs. Q5: OR: 3.48; 95\%Cl: 2.41-5.01] and the presence of public PA facilities near the household (Q1: OR: 3.07; 95\%Cl: 2.35-4.01 vs. Q5: OR: $1.38 ; 95 \% \mathrm{Cl}$ : 1.22-1.55) were more associated with higher odds of being active in the leisure-time among the lowest quintile of educational level.
\end{abstract}

Conclusions: The presence of public PA facilities and participation in public PA programs are environmental correlates that may be relevant for designing effective public health interventions to reduce social inequalities in leisuretime PA among adults in low-income areas.

Keywords: Exercise, Sedentary lifestyle, Inequalities, Education, Built environment

*Correspondence: andrewerneck@usp.br

${ }^{1}$ Center for Epidemiological Research in Nutrition and Health, Department of Nutrition, School of Public Health, University of São Paulo (USP), Av. Dr. Arnaldo, 715 - Cerqueira César, São Paulo, SP 01246-904, Brazil

Full list of author information is available at the end of the article

\section{Introduction}

Physical activity (PA) is a protective factor for different health outcomes, including cardiovascular diseases, mental disorders, cancer and all-cause mortality $[1,2]$. However, the proportion of adults who fail to reach the PA recommendation is elevated worldwide [3]. The health 
benefit of PA is domain specific [4]. Previous studies have shown that leisure-time PA presents the strongest associations with health outcomes, when compared with other domains such as transport and occupational PA [4-6].

Specifically in Brazil, leisure-time PA has increased over the years $[7,8]$, but this is mainly among people with higher educational level [8]. In this sense, the comprehension of factors that could reduce socioeconomic inequalities in leisure-time PA practice would help in the formulation of effective strategies for PA promotion across population sub-groups [9]. Considering the range of multi-level correlates of leisure-time PA, including individual (e.g., gender, age), interpersonal (e.g., social support), environmental (e.g., neighborhood walkability), regional and national policy (e.g., transport systems), and global (e.g., urbanization) [10], increasing opportunities for PA practice and participation is important for improving PA level, especially for the most vulnerable population groups [9]. Studies have found that several environmental correlates are associated with leisure-time PA, especially public PA facilities such as green areas and parks [10-12]. Also, community public programs to stimulate PA can increase leisure-time PA at the community level $[13,14]$. In this sense, the presence of public areas for the PA practice and the participation in public PA programs reduces the barriers to the achievement of the PA guidelines, becoming a facilitator of opportunities, which can hypothetically be enhanced when considering people with lower income levels, who have less opportunities to practice PA.

However, the majority of the previous studies did not include nationally representative samples when testing the association of the presence of public PA facilities and participation in public PA programs with leisure-time PA. In addition, the role of income and educational level in this association is not clear. Therefore, we aimed to analyze the association of the presence of public PA facilities and participation in public PA programs with leisure-time PA, with an emphasis on the moderating role of educational level and income. We hypothesize that the presence of public PA facilities and participation in public PA programs will be associated with leisure-time PA and considering the lower opportunities among people with lower educational level and income, the presence of public PA facilities and participation in public PA programs could have a stronger association with leisure-time PA in these groups.

\section{Methods}

\section{Sample}

We used data from the Brazilian National Health Survey, which was a cross-sectional epidemiological study, conducted with a nationally representative sample of people $\geq 15$ years old, during 2019 in Brazil. The sampling process was in three stages. Firstly, census tracts were randomly selected; next, households were randomly selected; and finally, in the households, one inhabitant ( $\geq 15$ years old) was randomly selected. More details of the sampling process and weighting have been previously published elsewhere [15]. From the initial 100,541 selected households, 94,114 interviews were conducted. Due to missing data and excluding adolescents, the final sample was composed of 88,531 adults ( $\geq 18$ years). Estimates were weighted considering the characteristics of the general population (i.e., sex and age group) as well as the non-response rate. The Brazilian Council of Ethics in Research approved all procedures according to the Helsinki declaration.

\section{Leisure-time PA}

Leisure-time PA was self-reported based on a questionnaire previously validated for Brazilian adults [16]. The questionnaire is composed of specific questions asking about frequency and duration of leisure-time PA in habitual activities. For classification, total minutes of leisure-time PA was calculated and classified using the cutoff point of $150 \mathrm{~min} /$ week.

\section{Participation in public PA programs and public PA facilities near the household}

The participation in public PA programs was assessed through the dichotomic questions (yes/no): "Do you know of any public program to encourage the practice of physical activity in your city?" and "Do you participate in this public program to encourage the practice of physical activity in your city?". The presence of public PA facilities near the household was also assessed through the dichotomic question (yes/no): "Is there a public place close to your home (square, park, closed street, beach) to walk, exercise or play sports?". The last two questions were adopted as exposures.

\section{Per capita income and educational level}

The per capita income and educational level were categorized as quintiles. For the quintiles of income, we considered the household per capita income in monetary value and divided into quintiles, which the first quintile (Q1) represents the lowest level and the fifth quintile (Q5) the highest level. The classification values were (in Brazilian reais - BRL): Q1: $\leq$ BRL417.00; Q2: $\geq$ BRL418.00 and $\leq$ BRL750.00; Q3: $\geq$ BRL750.00 and $\leq$ BRL1,099.00; Q4: $\geq$ BRL1,100.00 and $\leq$ BRL1,999.00; Q5: $\geq$ BRL2,000.00. For the quintiles of educational level, categories of highest educational achievement were grouped in order to have balanced groups in each survey (1- No education; 2- Primary incomplete; 3 - Primary complete 
or incomplete high school; 4- High school; 5- More than high school), based on a previous study [17].

\section{Confounders}

Gender, age group, TV-viewing, urban/rural and ethnicity were used as confounders in the analyzes. Age group was classified as 18-34y, 35-49y, 50-64y, and 65+. Ethnicity was assessed according to the self-reported skin color and classified as white, black, mixed, or other. TVviewing was self-reported and classified using the cut-off point of $\geq 3 \mathrm{~h} /$ day.

\section{Statistical procedures}

Characteristics of the sample were described using values of absolute and relative frequencies as well as $95 \%$ confidence interval. Logistic regression models were created to estimate the joint associations of participation in public PA programs and the presence of public PA facilities near the household with income and educational level in predicting leisure-time PA, adjusting for sex, age group, TV-viewing, urban/rural and ethnicity. In addition, multiplicative interactions were used to assess the moderation of income and educational level in the associations of participation in public PA programs and the presence of public PA facilities near the household with leisuretime PA. Also, the associations of participation in public PA programs and the presence of public PA facilities near the household with leisure-time PA stratifying by quintiles of per capita income and educational level were tested.

\section{Results}

The final sample was composed of 88,531 adults $(46,869$ women), with a mean age of $47.2 \pm 17.1$ years. The characteristics of the sample according to leisure-time PA are presented in Table 1. The proportion of men, young adults, with higher educational level, higher income, PA facilities near home and participating in PA programs was higher among participants active in leisure-time.

Figure 1 shows the prevalence of leisure-time PA, participation in PA programs and presence of public PA facilities near the household according to quintiles of per capita income and educational level. Higher quintiles of income and educational level presented a higher prevalence of leisure-time PA and presence of public PA facilities near the household. The participation in PA programs was similar according to the quintiles of income and educational level.

Figure 2 shows the prevalence of leisure-time PA according to quintiles of income and educational level as well as participation in PA programs and the presence of facilities near the household. The prevalence of leisuretime PA was higher among participants who engaged in
PA programs across all the quintiles of income and educational level. Similarly, the prevalence of leisure-time PA was higher among participants with public PA facilities near the household. However, this was more pronounced for participants in the lowest quintile of educational level, in which the prevalence of leisure-time PA was more than $100 \%$ higher among those with facilities near the household (18.5\% vs. $6.8 \%)$.

The combined associations of educational level and income with PA programs and public PA facilities near the household in the association with leisure-time PA are presented in Table 2. Multiplicative interactions revealed that participating in PA programs (Quintile 1: OR: 13.99; 95\%CI: $6.89-28.38$ vs. Quintile 5: OR: 3.48 ; $95 \% \mathrm{CI}$ : 2.41-5.01) and the presence of public PA facilities near the household (Quintile 1: OR: 3.07; 95\%CI: 2.35-4.01 vs. Quintile 5: OR: 1.38; 95\%CI: 1.22-1.55) were more associated with lower odds of engaging in leisure-time PA in the lowest quintile of educational level.

\section{Discussion}

We aimed to investigate the association of the presence of public PA facilities near the household and participation in public programs of PA with leisure-time PA as well as whether income and educational level could moderate this association, using a nationally representative sample of Brazilian adults. Our main findings were that the presence of public PA facilities near the household and participation in public PA programs were associated with higher leisure-time PA among all quintiles of income and educational level. However, these associations were more pronounced among the lowest quintiles of educational level and income.

Our findings confirm that the presence of public PA facilities near the household and participation in public PA programs are associated with a higher leisure-time PA practice as reported in previous findings $[12,13,18,19]$. Although both correlates were associated with higher leisure-time PA across all quintiles of income and educational level, the association was stronger in the lowest educational level group. These findings highlight that PA policies should be more decisive for PA promotion among the poorest as the opportunities for PA practice are lower in this group [9].

There are marked PA inequalities especially in the leisure-time domain, in which people with higher educational level and income present higher PA practice $[7,8]$. In this sense, the increases in leisure-time PA levels over the years in Brazil is somewhat contrasting with the also increasing socioeconomic inequalities in the practice of leisure-time PA [8]. Considering the context of inequalities in leisure-time PA and the more decisive role of public PA facilities and participation in public PA programs, 
Table 1 Characteristics of the sample according to leisure-time physical activity practice

\begin{tabular}{|c|c|c|c|c|c|c|c|}
\hline & & \multirow{2}{*}{\multicolumn{2}{|c|}{$\begin{array}{l}\text { Whole sample } \\
n=88,531\end{array}$}} & \multicolumn{4}{|c|}{ Active in leisure-time } \\
\hline & & & & \multicolumn{2}{|c|}{ No $(n=66,278)$} & \multicolumn{2}{|c|}{ Yes $(n=22,253)$} \\
\hline & & $\mathbf{n}$ & $\%$ & $\mathbf{n}$ & $\%$ & $\mathbf{n}$ & $\%$ \\
\hline \multirow[t]{2}{*}{ Gender } & Male & 41,662 & $46.8(46.3-47.4)$ & 30,985 & $45.7(45.0-46.4)$ & 10,677 & $50.1(48.9-51.3)$ \\
\hline & Female & 46,869 & $53.2(52.6-53.7)$ & 35,293 & $54.3(53.6-55.0)$ & 11,576 & $49.9(48.7-51.1)$ \\
\hline \multirow[t]{4}{*}{ Ethnicity } & White & 32,409 & $43.3(42.7-43.9)$ & 23,642 & $42.2(41.6-42.9)$ & 8767 & $46.1(44.9-47.3)$ \\
\hline & Black & 10,132 & $11.5(11.1-11.8)$ & 7619 & $11.6(11.2-12.0)$ & 2513 & $11.1(10.4-11.8)$ \\
\hline & Mixed & 44,646 & $43.8(43.2-44.4)$ & 34,023 & $44.7(44.0-45.4)$ & 10,623 & $41.3(40.2-42.5)$ \\
\hline & Other & 1344 & $1.5(1.3-1.6)$ & 994 & $1.5(1.3-1.7)$ & 350 & $1.5(1.2-1.8)$ \\
\hline \multirow[t]{2}{*}{ Type of residence } & Urban & 68,220 & $86.2(85.9-86.5)$ & 48,825 & $84.1(83.7-84.5)$ & 19,395 & $91.9(91.4-92.3)$ \\
\hline & Rural & 20,311 & $13.8(13.5-14.1)$ & 17,453 & $15.9(15.5-16.3)$ & 2858 & $8.1(7.7-8.6)$ \\
\hline \multirow[t]{4}{*}{ Age group } & $18-34$ & 24,115 & $32.0(31.4-32.5)$ & 16,420 & $29.3(28.6-29.9)$ & 7695 & $39.4(38.3-40.6)$ \\
\hline & $35-49$ & 26,031 & $29.3(28.8-29.8)$ & 19,119 & $29.2(28.5-29.8)$ & 6912 & $29.7(28.7-30.8)$ \\
\hline & $50-64$ & 21,198 & $22.6(22.1-23.1)$ & 16,410 & $23.5(22.9-24.0)$ & 4788 & $20.3(19.4-21.2)$ \\
\hline & $65+$ & 17,187 & $16.1(15.7-16.5)$ & 14,329 & $18.1(17.7-18.6)$ & 2858 & $10.5(9.9-11.2)$ \\
\hline \multirow[t]{5}{*}{ Educational level } & Q1 & 7632 & $6.1(5.9-6.3)$ & 6910 & $7.4(7.1-7.7)$ & 722 & $2.6(2.2-3.0)$ \\
\hline & Q2 & 27,940 & $28.7(28.2-29.2)$ & 23,799 & $32.9(32.3-33.5)$ & 4141 & $16.9(16.1-17.7)$ \\
\hline & Q3 & 12,005 & $14.5(14.1-14.9)$ & 9339 & $15.2(14.7-15.7)$ & 2666 & $12.4(11.6-13.2)$ \\
\hline & Q4 & 23,378 & $29.8(29.2-30.4)$ & 16,409 & $28.3(27.7-28.9)$ & 6969 & $34.0(32.8-35.2)$ \\
\hline & Q5 & 17,576 & $21.0(20.5-21.4)$ & 9821 & $16.2(15.7-16.7)$ & 7755 & $34.2(33.1-35.3)$ \\
\hline \multirow[t]{5}{*}{ Income } & Q1 & 17,681 & $16.9(16.5-17.3)$ & 14,515 & $18.8(18.3-19.3)$ & 3188 & $11.7(11.1-12.4)$ \\
\hline & Q2 & 17,837 & $20.9(20.5-21.4)$ & 14,145 & $22.3(21.7-22.8)$ & 3692 & $17.2(16.4-18.1)$ \\
\hline & Q3 & 17,553 & $19.2(18.8-19.7)$ & 13,888 & $20.1(19.5-20.6)$ & 3665 & $16.9(16.0-17.8)$ \\
\hline & Q4 & 17,716 & $22.7(22.2-23.2)$ & 13,027 & $22.3(21.7-22.9)$ & 4667 & $23.7(22.6-24.8)$ \\
\hline & Q5 & 17,744 & $20.3(19.8-20.7)$ & 10,710 & $16.6(16.1-17.1)$ & 7034 & $30.5(29.4-31.6)$ \\
\hline \multirow[t]{2}{*}{ TV-viewing } & $<3 h$ & 69,282 & $78.2(77.7-78.7)$ & 51,278 & 77.4 (76.9-78.0) & 18,004 & 80.5 (79.4-81.5) \\
\hline & $\geq 3 \mathrm{~h}$ & 19,249 & $21.8(21.3-22.3)$ & 15,000 & $22.6(22.0-23.1)$ & 4249 & 19.5 (18.5-20.6) \\
\hline \multirow[t]{2}{*}{ PA programs participation } & No & 86,169 & $97.3(97.1-97.5)$ & 65,287 & $98.4(98.3-98.6)$ & 20,882 & $94.0(93.5-94.5)$ \\
\hline & Yes & 2362 & $2.7(2.5-2.9)$ & 991 & $1.6(1.4-1.7)$ & 1371 & $6.0(5.5-6.5)$ \\
\hline \multirow[t]{2}{*}{ PA facilities near household } & No & 45,201 & $56.2(55.6-56.8)$ & 30,670 & $47.7(47.0-48.4)$ & 14,531 & $67.1(66.0-68.3)$ \\
\hline & Yes & 43,330 & $43.8(43.2-44.4)$ & 35,608 & $52.3(51.6-53.0)$ & 7722 & $32.9(31.7-34.0)$ \\
\hline
\end{tabular}

Note. Values of relative frequencies are weighted. $Q$, quintile. Both quintiles of income and educational level are based on the distribution of the sample into quintiles. As it was not possible to estimate the number of educational years, the closest categorization of quintiles was: Q1- No education; Q2- Primary incomplete; Q3- Primary complete or incomplete high school; Q4- High school; Q5- More than high school

it is noteworthy that a higher proportion of people in the highest quintile of educational level and income reported the presence of public PA facilities near the household. This finding is consistent with previous Brazilian finding [20] as well as from other countries [21] and underscore the urgent need to address disparity and inequality in presence of PA facilities in low-income areas and disadvantaged regions of Brazil.
Our findings highlight that the building and revitalization of public PA facilities such as parks and recreational centers for PA practice need to be prioritized in areas with lower socioeconomic development. Despite the association with PA, the proximity to public PA facilities could also be positive for well-being and quality of life [22]. However, a frequent consequence of revitalization is the increasing gentrification and hygienisation in the surrounding areas, which could cause an urban

(See figure on next page.)

Fig. 1 The prevalence of leisure-time PA, participation in public PA programs and the presence of public PA facilities near the household according to quintiles of educational level and income. Note. PA, physical activity. Q, quintile. Both quintiles of income and educational level are based on the distribution of the sample into quintiles. As it was not possible to estimate the number of education years, the closest categorization of quintiles was: Q1- No education; Q2- Primary incomplete; Q3- Primary complete or incomplete high school; Q4- High school; Q5- More than high school 


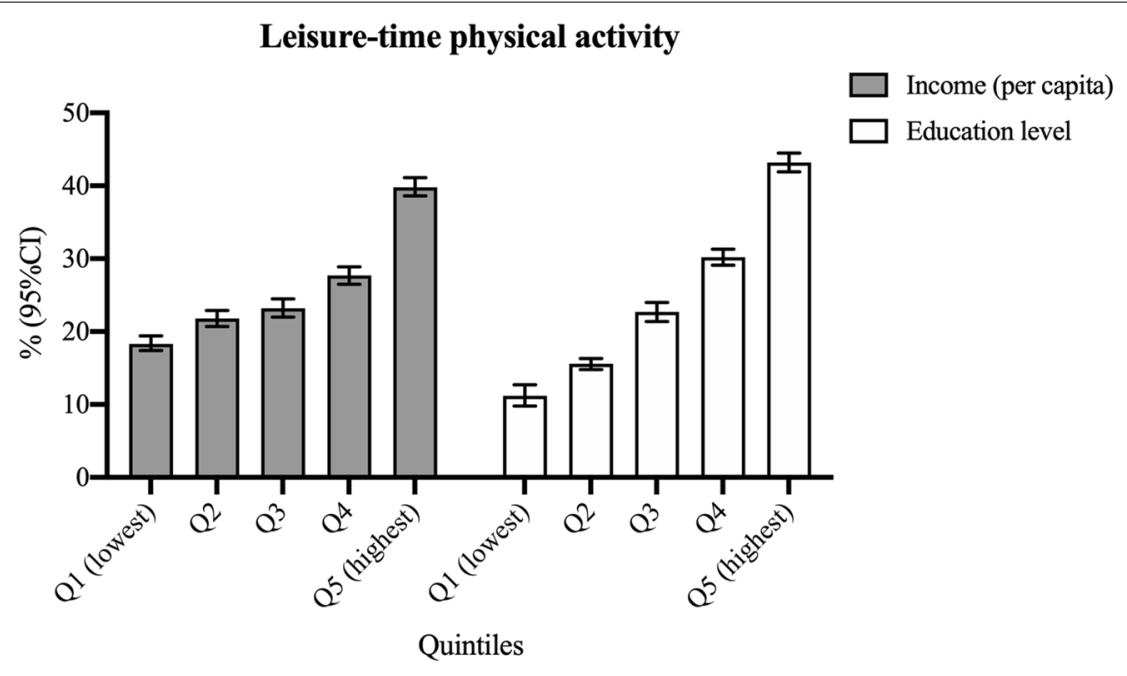

Participation in public PA programs

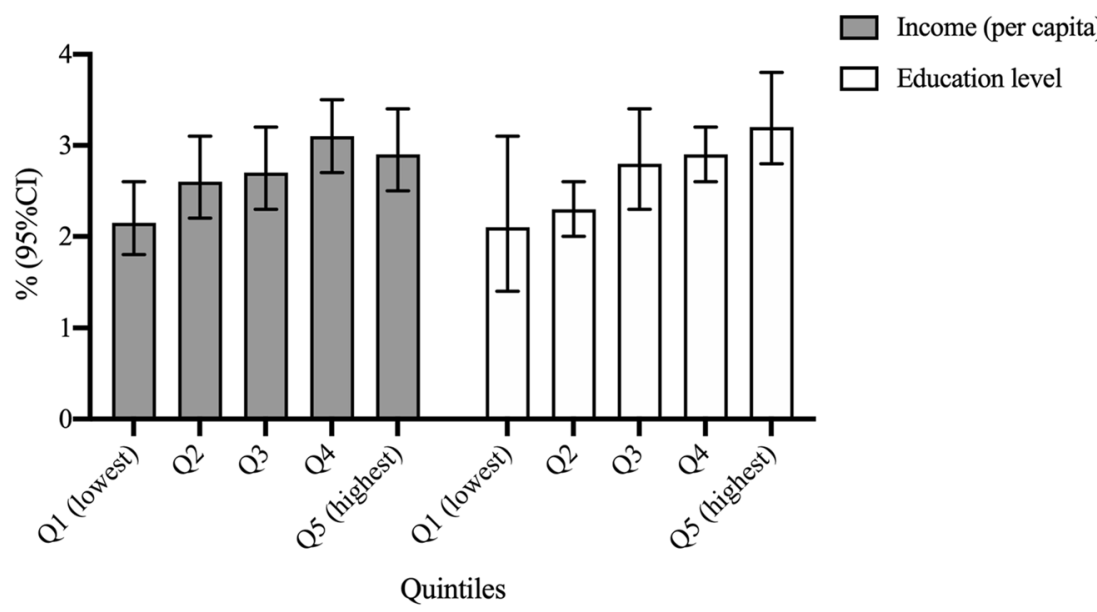

Presence of public PA facilities near the household

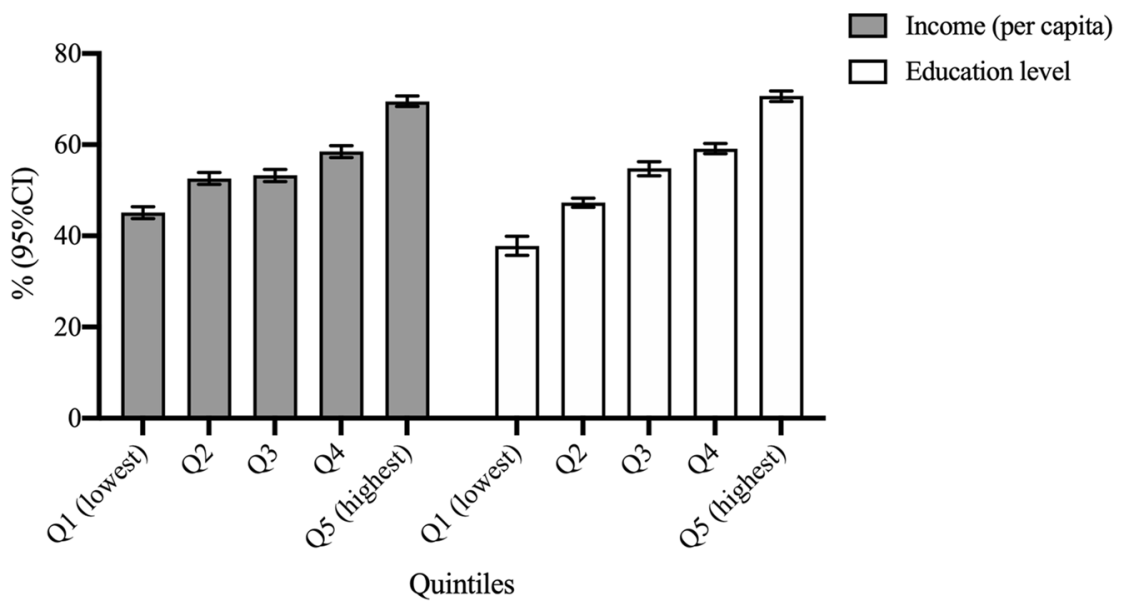

Fig. 1 (See legend on previous page.) 

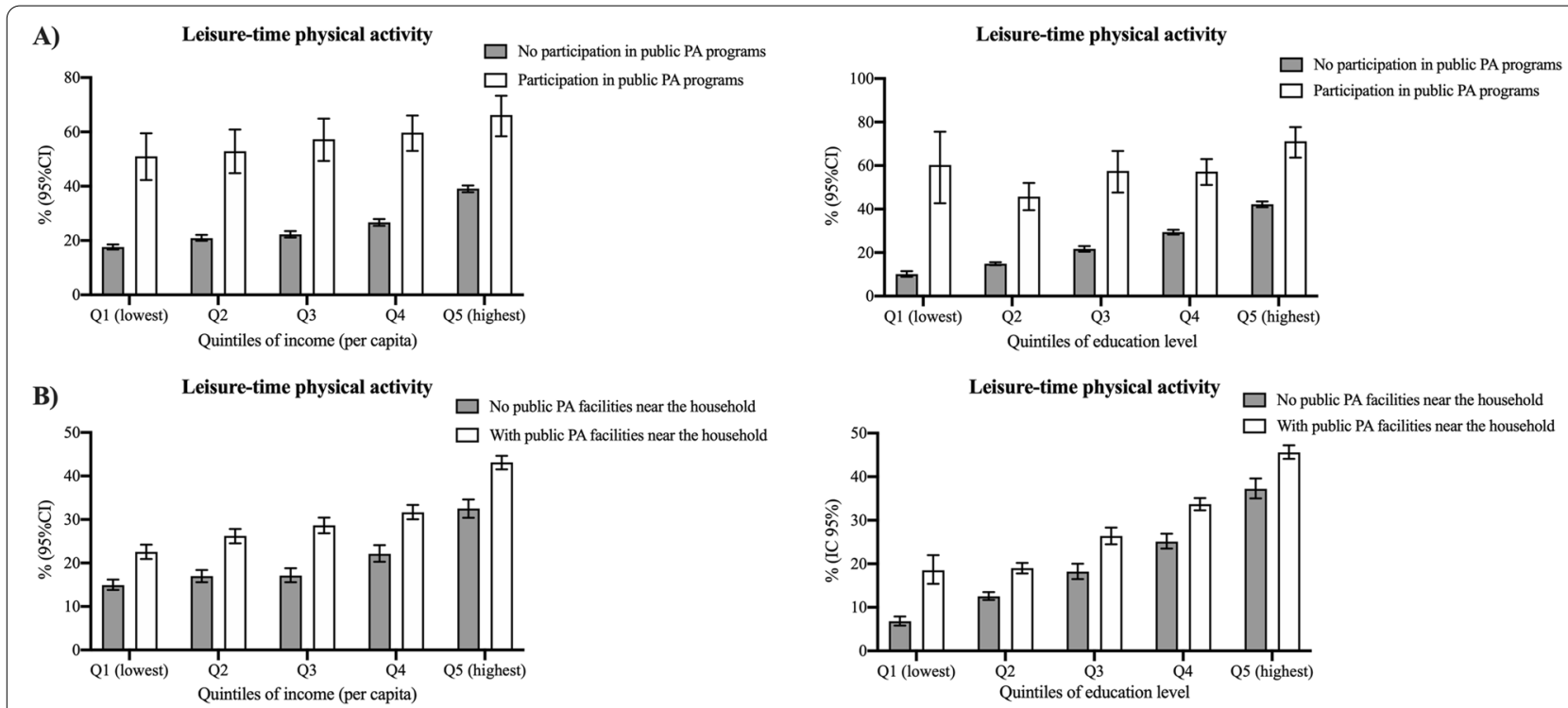

Fig. 2 Prevalence of $\geq 150 \mathrm{~min} /$ week of leisure-time physical activity according to quintiles of educational level and income as well as the prevalence of physical activity public programs and public PA facilities. Note. PA, physical activity. Q, quintile. Both quintiles of income and educational level are based on the distribution of the sample into quintiles. As it was not possible to estimate the number of education years, the closest categorization of quintiles was: Q1- No education; Q2- Primary incomplete; Q3- Primary complete or incomplete high school; Q4- High school; Q5- More than high school

displacement of people with lower socioeconomic conditions from the revitalized areas to areas without public facilities [23, 24]. Some actions could help to avoid gentrification, such as involving the community in the planning of the revitalizations as well as creating measures to avoid the real estate speculation throughout the surrounding areas [25].

Also, the expansion of community health programs for the stimulation of PA should be prioritized, especially in deprived areas. Although Brazil has a large program that includes PA professionals in primary health care (Multidisciplinary Primary Care Teams), the distribution of the units with PA interventions is unequal considering different geographical regions [26]. The supervised PA promoted by the different programs already proved to be effective, even in highly deprived areas, such as in "favelas" [14, 27]. Also, both the building of public PA facilities and the stimulation of community health programs for the stimulation of PA should be taken together. For example, analyzing data from the same Brazilian National Survey (adjusting for the same confounders), participants living in areas with a public PA facility near the household were 268\% (OR:3.69; 95\%CI:3.03-4.50) more likely to participate in public PA programs, highlighting that most of the programs occurs in public PA facilities. In this sense, building PA facilities in more deprived regions would also contribute to the expansion and engagement of people with lower socioeconomic status in public
PA programs. In addition, considering the difference observed between the frequency of public PA facilities, leisure-time PA and participation in public PA programs across categories of educational level and income, further investigations are needed in order to identify strategies to optimize the use of public PA facilities.

The strength of our study is including a large nationally representative sample of Brazilian adults with data on PA, proximity to public PA facilities, income and educational level. However, our findings should be inferred in light of possible limitations. First, our study has a cross-sectional design and causal relations should be avoided. Second, our findings were based on self-reported measures, which can present bias. Third, the levels of participation in public PA programs were considerably low, which is a reflection of the low coverage of health programs involving physical education professionals, which may have reduced the sampling power. However, up to the moment, there is no feasible method to estimate domains of PA in large population studies. Also, both perceived and objectively-assessed built environmental characteristics are associated with PA [11].

In conclusion, we found participation in public PA programs and presence of public PA facilities near the household to be associated with higher leisure-time PA and the associations are stronger in the group with lower educational level. Our findings suggest that presence of public 
Table 2 Joint associations of educational level and income with physical activity programs and public physical activity facilities near the household in the association with leisure-time physical activity

\begin{tabular}{|c|c|c|c|}
\hline & $\begin{array}{l}\text { Joint } \\
\text { OR }(95 \% \mathrm{Cl})\end{array}$ & $\begin{array}{l}\text { Multiplicative interaction } \\
\text { OR }(95 \% \mathrm{Cl})\end{array}$ & $\begin{array}{l}\text { Stratified } \\
\text { OR }(95 \% \mathrm{Cl})\end{array}$ \\
\hline \multicolumn{4}{|c|}{ Educational level + PA programs } \\
\hline $\mathrm{Q} 5+\mathrm{No}$ & REF & REF & REF \\
\hline Q5 + Yes & $3.48(2.42-5.00)$ & - & $3.48(2.41-5.01)$ \\
\hline $\mathrm{Q} 4+\mathrm{No}$ & $0.57(0.52-0.61)$ & - & REF \\
\hline Q4+Yes & $1.96(1.52-2.51)$ & $0.99(0.64-1.54)$ & $3.52(2.74-4.51)$ \\
\hline $\mathrm{Q} 3+\mathrm{No}$ & $0.38(0.35-0.42)$ & - & REF \\
\hline $\mathrm{Q} 3+$ Yes & $1.98(1.33-2.93)$ & $1.48(0.86-2.53)$ & $5.35(3.59-7.96)$ \\
\hline $\mathrm{Q} 2+\mathrm{No}$ & $0.28(0.26-0.30)$ & - & REF \\
\hline $\mathrm{Q} 2+$ Yes & $1.42(1.09-1.85)$ & $1.46(0.94-2.29)$ & $4.80(3.69-6.24)$ \\
\hline $\mathrm{Q} 1+\mathrm{No}$ & $0.20(0.17-0.23)$ & - & REF \\
\hline $\mathrm{Q} 1+$ Yes & $2.81(1.35-5.84)$ & $4.06(1.78-9.26)$ & $13.99(6.89-28.38)$ \\
\hline \multicolumn{4}{|c|}{ Income + PA programs } \\
\hline $\mathrm{Q} 5+\mathrm{No}$ & REF & REF & REF \\
\hline Q5+Yes & $3.34(2.33-4.78)$ & - & $3.26(2.27-4.68)$ \\
\hline $\mathrm{Q} 4+\mathrm{No}$ & $0.55(0.50-0.60)$ & - & REF \\
\hline $\mathrm{Q} 4+$ Yes & $2.53(1.86-3.42)$ & $1.38(0.86-2.22)$ & $4.50(3.31-6.10)$ \\
\hline $\mathrm{Q} 3+\mathrm{No}$ & $0.45(0.41-0.49)$ & - & REF \\
\hline Q3+Yes & $2.43(1.70-3.45)$ & $1.62(0.98-2.68)$ & $5.67(3.94-8.17)$ \\
\hline $\mathrm{Q} 2+\mathrm{No}$ & $0.38(0.35-0.41)$ & - & REF \\
\hline $\mathrm{Q} 2+$ Yes & $1.72(1.22-2.42)$ & $1.36(0.83-2.23)$ & $4.55(2.23-6.39)$ \\
\hline $\mathrm{Q} 1+\mathrm{No}$ & $0.30(0.27-0.33)$ & - & REF \\
\hline $\mathrm{Q} 1+$ Yes & $1.43(1.01-2.00)$ & $1.42(0.86-2.33)$ & $5.16(3.69-7.22)$ \\
\hline \multicolumn{4}{|c|}{ Educational level + facilities } \\
\hline $\mathrm{Q} 5+\mathrm{No}$ & REF & REF & REF \\
\hline Q5+Yes & $1.39(1.24-1.56)$ & - & $1.38(1.22-1.55)$ \\
\hline $\mathrm{Q} 4+\mathrm{No}$ & $0.56(0.49-0.64)$ & - & REF \\
\hline Q4+Yes & $0.83(0.74-0.93)$ & $1.06(0.90-1.24)$ & $1.46(1.31-1.64)$ \\
\hline $\mathrm{Q} 3+\mathrm{No}$ & $0.38(0.32-0.44)$ & - & REF \\
\hline $\mathrm{Q} 3+$ Yes & $0.59(0.51-0.68)$ & $1.12(0.92-1.36)$ & $1.56(1.32-1.83)$ \\
\hline $\mathrm{Q} 2+\mathrm{No}$ & $0.28(0.24-0.32)$ & - & REF \\
\hline $\mathrm{Q} 2+$ Yes & $0.43(0.38-0.49)$ & $1.12(0.95-1.32)$ & $1.59(1.40-1.79)$ \\
\hline $\mathrm{Q} 1+\mathrm{No}$ & $0.15(0.13-0.19)$ & - & REF \\
\hline $\mathrm{Q} 1+$ Yes & $0.45(0.35-0.57)$ & $2.10(1.56-2.83)$ & $3.07(2.35-4.01)$ \\
\hline \multicolumn{4}{|c|}{ Income + facilities } \\
\hline $\mathrm{Q} 5+\mathrm{No}$ & REF & REF & REF \\
\hline Q5+Yes & $1.49(1.32-1.67)$ & - & $1.44(1.28-1.62)$ \\
\hline $\mathrm{Q} 4+\mathrm{No}$ & $0.57(0.49-0.66)$ & - & REF \\
\hline $\mathrm{Q} 4+$ Yes & $0.86(0.76-0.98)$ & $1.02(0.85-1.22)$ & $1.49(1.30-1.71)$ \\
\hline $\mathrm{Q} 3+\mathrm{No}$ & $0.44(0.38-0.51)$ & - & REF \\
\hline $\mathrm{Q} 3+$ Yes & $0.76(0.66-0.86)$ & $1.16(0.89-1.27)$ & $1.73(1.48-2.01)$ \\
\hline $\mathrm{Q} 2+\mathrm{No}$ & $0.39(0.34-0.45)$ & - & REF \\
\hline $\mathrm{Q} 2+$ Yes & $0.61(0.54-0.70)$ & $1.06(0.89-1.27)$ & $1.60(1.40-1.84)$ \\
\hline $\mathrm{Q} 1+\mathrm{No}$ & $0.32(0.28-0.37)$ & - & REF \\
\hline $\mathrm{Q} 1+$ Yes & $0.49(0.42-0.56)$ & $1.02(0.85-1.22)$ & $1.59(1.38-1.84)$ \\
\hline
\end{tabular}

Note. Adjusted for sex, age group, TV-viewing, urban/rural and ethnicity. OR odds ratio, $\mathrm{Cl}$ confidence interval. Q, quintile. Both quintiles of income and educational level are based on the distribution of the sample into quintiles. As it was not possible to estimate the number of education years, the closest categorization of quintiles was: Q1 - No education; Q2- Primary incomplete; Q3Primary complete or incomplete high school; Q4- High school; Q5- More than high school
PA facilities and participation in public PA programs are built environmental correlates that could be relevant for designing effective public health intervention for reducing social inequalities in leisure-time PA among adults in low-income areas of Brazil. Future studies should evaluate whether revitalization and the building of open spaces in areas of lower socioeconomic conditions could increase leisure-time PA among people with lower socioeconomic status.

\section{Acknowledgements}

We would like to thank the Brazilian Institute of Geography and Statistics for the collection and availability of data.

\section{Authors' contributions}

AOW: Concept and study design, data analysis, interpretation of the data and drafted the initial manuscript. ALO, RHOA, LLB, CLS and DRS: Critical revision and approval of the manuscript for important intellectual content. All authors have read and approved the final version of the manuscript and agree with the order of presentation of the authors.

\section{Funding}

This research received no specific grant from any funding agency in the public, commercial, or not-for-profit sectors. André Werneck is supported by the São Paulo Research Foundation (FAPESP) with a PhD scholarship (FAPESP process: 2019/24124-7). Raphael Araújo is supported by the Coordination for the Improvement of Higher Education Personnel (CAPES) with a PhD scholarship (CAPES process: 88887.605034/2021-00). This paper presents independent research. The views expressed in this publication are those of the authors and not necessarily those of the acknowledged institution.

\section{Availability of data and materials}

Data from the National Health Survey is available in the Brazilian Institute of Geography and Statistics website (https://www.ibge.gov.br/en/home-eng. html).

\section{Declarations}

\section{Ethics approval and consent to participate}

All procedures performed in the original study involving human participants were approved by the Comissão Nacional de Ética em Pesquisa (CONEP: 3.529.376).

\section{Consent for publication}

Not applicable.

\section{Competing interests}

The authors declare that they have no competing interests.

\section{Author details}

${ }^{1}$ Center for Epidemiological Research in Nutrition and Health, Department of Nutrition, School of Public Health, University of São Paulo (USP), Av. Dr. Arnaldo, 715 - Cerqueira César, São Paulo, SP 01246-904, Brazil. ²Department of Physiotherapy, College of Medical Sciences, University of Maiduguri, Maiduguri, Borno State, Nigeria. ${ }^{3}$ Graduation Program in Health Sciences, Londrina State University, Londrina, Brazil. ${ }^{4}$ Postgraduate Program in Physical Education, University of Brasília (UnB), Brasília, Brazil. ${ }^{5}$ Instituto de Comunicação e Informação Científica e Tecnológica em Saúde (ICICT), Fundação Oswaldo Cruz (Fiocruz), Rio de Janeiro, Brazil. ${ }^{6}$ Department of Physical Education, Federal University of Sergipe - UFS, São Cristóvão, Brazil.

Received: 3 June 2021 Accepted: 18 January 2022

Published online: 11 February 2022 


\section{References}

1. Firth J, Solmi M, Wootton RE, Vancampfort D, Schuch FB, Hoare E, et al. A meta-review of "lifestyle psychiatry": the role of exercise, smoking, diet and sleep in the prevention and treatment of mental disorders. World Psychiatry. 2020;19(3):360-80. https://doi.org/10.1002/wps.20773.

2. Lee I-M, Shiroma EJ, Lobelo F, Puska P, Blair SN, Katzmarzyk PT. Effect of physical inactivity on major non-communicable diseases worldwide: an analysis of burden of disease and life expectancy. Lancet. 2012;380(9838):219-29. https://doi.org/10.1016/S0140-6736(12)61031-9.

3. Guthold R, Stevens GA, Riley LM, Bull FC. Worldwide trends in insufficient physical activity from 2001 to 2016: a pooled analysis of 358 population-based surveys with 1.9 million participants. Lancet Glob Health 2018;6(10):e1077-86. https://doi.org/10.1016/S2214-109X(18)30357-7.

4. Holtermann A, Schnohr P, Nordestgaard BG, Marott JL. The physical activity paradox in cardiovascular disease and all-cause mortality: the contemporary Copenhagen general population study with 104046 adults. Eur Heart J. 2021; ehab087. https://doi.org/10.1093/eurheartj/ehab087.

5. Autenrieth CS, Baumert J, Baumeister SE, Fischer B, Peters A, Döring A et al. Association between domains of physical activity and all-cause, cardiovascular and cancer mortality. Eur J Epidemiol. 2011:26(2):91-9. https://doi.org/10.1007/s10654-010-9517-6.

6. White RL, Babic MJ, Parker PD, Lubans DR, Astell-Burt T, Lonsdale C. Domain-specific physical activity and mental health: a meta-analysis. Am J Prev Med. 2017;52(5):653-66. https://doi.org/10.1016/j.amepre.2016.12. 008.

7. Dias TG, Nunes AP, Santos CD, Cruz MD, Guerra PH, Bernal RT, et al. Nível de atividade física no lazer em adultos paulistanos: uma análise de tendência de 2006 a 2016. Revista Brasileira de Epidemiologia. 2020;23:e200099. https://doi.org/10.1590/1980-549720200099.

8. Mielke Gl, Hallal PC, Malta DC, Lee I-M. Time trends of physical activity and television viewing time in Brazil: 2006-2012. Int J Behav Nutr Phys Act. 2014;11(1):101. https://doi.org/10.1186/s12966-014-0101-4.

9. Crochemore-Silva I, Knuth AG, Mielke Gl, Loch MR. Promoção de atividade física e as políticas públicas no combate às desigualdades: reflexões a partir da lei dos Cuidados Inversos e Hipótese da Equidade Inversa. Cadernos de Saúde Pública. 2020;36(6):e00155119. https://doi.org/10. 1590/0102-311x00155119.

10. Bauman AE, Reis RS, Sallis JF, Wells JC, Loos RJ, Martin BW. Correlates of physical activity: why are some people physically active and others not? Lancet. 2012;380(9838):258-71. https://doi.org/10.1016/S0140-6736(12) 60735-1.

11. Elshahat $S, O^{\prime}$ Rorke $M$, Adlakha D. Built environment correlates of physical activity in low- and middle-income countries: a systematic review. PLOS One. 2020;15(3):e0230454. https://doi.org/10.1371/journal.pone.0230454.

12. Sugiyama T, Cerin E, Owen N, Oyeyemi AL, Conway TL, Van Dyck D, et al. Perceived neighbourhood environmental attributes associated with adults' recreational walking: IPEN adult study in 12 countries. Health Place. 2014;28:22-30. https://doi.org/10.1016/j.healthplace.2014.03.003.

13. Reis RS, Hallal PC, Parra DC, Ribeiro IC, Brownson RC, Pratt M, et al. Promoting physical activity through community-wide policies and planning: findings from Curitiba, Brazil. J Phys Act Health. 2010;7(s2):S137-45. https://doi.org/10.1123/jpah.7.s2.s137.

14. Reis RS, Salvo D, Ogilvie D, Lambert EV, Goenka S, Brownson RC. Scaling up physical activity interventions worldwide: stepping up to larger and smarter approaches to get people moving. Lancet. 2016;388(10051):1337-48. https://doi.org/10.1016/S0140-6736(16) 30728-0.

15. Instituto Brasileiro de Geografia e Estatística. Pesquisa nacional de saúde: 2019: percepção do estado de saúde, estilos de Vida, doenças crônicas e saúde bucal. Rio de Janeiro: Instituto Brasileiro de Geografia e Estatística; 2020

16. Moreira AD, Claro RM, Felisbino-Mendes MS, Velasquez-Melendez G Validade e reprodutibilidade de inquérito telefônico de atividade física no Brasil. Revista Brasileira de Epidemiologia. 2017;20(1):136-46. https://doi. org/10.1590/1980-5497201700010012.

17. Jiwani SS, Carrillo-Larco RM, Hernández-Vásquez A, Barrientos-Gutiérrez T, Basto-Abreu A, Gutierrez L, et al. The shift of obesity burden by socioeconomic status between 1998 and 2017 in Latin America and the Caribbean: a cross-sectional series study. Lancet Glob Health. 2019;7(12):e1644-54. https://doi.org/10.1016/S2214-109X(19)30421-8.
18. Sallis JF, Cerin E, Conway TL, Adams MA, Frank LD, Pratt M, et al. Physical activity in relation to urban environments in 14 cities worldwide: a crosssectional study. Lancet. 2016;387(10034):2207-17. https://doi.org/10. 1016/S0140-6736(15)01284-2.

19. Schipperijn J, Cerin E, Adams MA, Reis R, Smith G, Cain K, et al. Access to parks and physical activity: an eight country comparison. Urban For Urban Green. 2017;27:253-63. https://doi.org/10.1016/j.ufug.2017.08.010.

20. Manta SW, Reis RS, Benedetti TRB, Rech CR. Public open spaces and physical activity: disparities of resources in Florianópolis. Rev Saude Publica. 2019;53:112. https://doi.org/10.11606/S1518-8787.2019053001164.

21. Rigolon A. A complex landscape of inequity in access to urban parks: a literature review. Landsc Urban Plan. 2016;153:160-9. https://doi.org/10. 1016/j.landurbplan.2016.05.017.

22. Wood L, Hooper P, Foster S, Bull F. Public green spaces and positive mental health - investigating the relationship between access, quantity and types of parks and mental wellbeing. Health Place. 2017:48:63-71. https://doi.org/10.1016/j.healthplace.2017.09.002.

23. Garmany J, Richmond MA. Hygienisation, gentrification, and urban displacement in Brazil. Antipode. 2020;52(1):124-44. https://doi.org/10. 1111/anti.12584.

24. Jelks NO, Jennings V, Rigolon A. Green gentrification and health: a scoping review. Int J Environ Res Public Health. 2021;18(3):907. https://doi.org/ 10.3390/ijerph18030907.

25. Thurber A, Krings A, Martinez LS, Ohmer M. Resisting gentrification: the theoretical and practice contributions of social work. J Soc Work. 2021;21(1):26-45. https://doi.org/10.1177/1468017319861500.

26. de Oliveira Gomes GA, Kokubun E, Mieke Gl, Ramos LR, Pratt M, Parra DC, et al. Characteristics of physical activity programs in the Brazilian primary health care system. Cadernos de Saúde Pública. 2014;30(10):2155-68. https://doi.org/10.1590/0102-311X00085713.

27. Lima AM, Werneck $A O$, Cyrino E, Farinatti P. Supervised training in primary care units but not self-directed physical activity lowered cardiovascular risk in Brazilian low-income patients: a controlled trial. BMC Public Health. 2019;19(1):1738. https://doi.org/10.1186/s12889-019-7716-y.

\section{Publisher's Note}

Springer Nature remains neutral with regard to jurisdictional claims in published maps and institutional affiliations.

Ready to submit your research? Choose BMC and benefit from

- fast, convenient online submission

- thorough peer review by experienced researchers in your field

- rapid publication on acceptance

- support for research data, including large and complex data types

- gold Open Access which fosters wider collaboration and increased citations

- maximum visibility for your research: over 100M website views per year

At BMC, research is always in progress.

Learn more biomedcentral.com/submissions 